Revista

Ibero-Americana

de Estratégia

\title{
APPLICATION OF METHODOLOGY OF THE BALANCED SCORECARD SYSTEM FOR QUALITY EVALUATION OF A STRATEGIC BUSINESS UNIT
}

\section{APLICACIÓN DE LA METODOLOGÍA DEL SISTEMA DE EVALUACIÓN CUADRO DE MANDO PARA LA CALIDAD DE UNA UNIDAD ESTRATÉGICA DE NEGOCIOS}

\section{Sandra Aparecida Nogueira de Oliveira Boffi}

Mestre em Gestão e Desenvolvimento Regional pela Universidade de Taubaté - UNITAU

Professora da Faculdade Anhanguera

E-mail: sandra.boffi@uol.com.br (Brasil)

Edson Aparecida de Araújo Querido Oliveira

Doutor em Engenharia Aeronáutica e Mecânica pelo Instituto Tecnológico de Aeronáutica - ITA Professor da Universidade de Taubaté - UNITAU

E-mail: edsonaaqo@gmail.com (Brasil)

\section{Monica Franchi Carnielo}

Doutora em Comunicação e Semiótica pela Pontifícia Universidade Católica de São Paulo PUC/SP

Professora da Universidade de Taubaté - UNITAU

E-mail: isa.santos.sjc@gmail.com (Brasil)

\section{Vilma da Silva Santos}

Mestre pelo Programa Profissional em Gestão e Desenvolvimento Regional pela Universidade de Taubaté - UNITAU

Professora da Universidade de Taubaté - UNITAU

E-mail: vilma70@gmail.com (Brasil) 


\title{
APLICAÇÃO DA METODOLOGIA DO BALANCED SCORECARD NO SISTEMA DE AVALIAÇÃO DA QUALIDADE DE UMA UNIDADE ESTRATÉGICA DE NEGÓCIOS
}

\section{RESUMO}

As organizações atuais são cobradas para terem o domínio da tecnologia, possuírem qualidade comprovada pelos padrões mundiais e para serem empreendimentos que atendam às expectativas sempre mutáveis dos clientes, cada vez mais exigentes. Para sobreviver nesse ambiente competitivo é necessário que desenvolvam ferramentas capazes de definir sua posição frente ao mercado, seus processos internos frente aos seus próprios objetivos e sua prospecção para o futuro. Tais ferramentas devem ser capazes de identificar seus pontos fortes e fracos, a fim de proporcionar o fortalecimento da sua posição e definição do melhor caminho a ser seguido, mesmo que este represente a mudança total de direção. $\mathrm{O}$ objetivo deste trabalho é analisar e descrever as etapas para o desenvolvimento de indicadores de desempenho integrados e baseados na estratégia global da empresa, conforme metodologia do Balanced Scorecard, focados na sustentabilidade da organização, e em atingir as metas previamente estabelecidas pela administração corporativa. A presente pesquisa utiliza-se de dados bibliográficos dos temas referentes à Administração Corporativa, Controle, Mensuração de Desempenho e Modelos de Indicadores de Desempenho. Com a utilização do estudo de caso documental como método de pesquisa conclui-se que os indicadores de desempenho são ferramentas vitais quando estruturados a fim de atender as perspectivas financeiras, dos clientes, dos processos internos e do aprendizado e crescimento da organização.

Palavras-chave: Administração Corporativa; Indicadores de Desempenho; Balanced Scorecard.

\section{APPLICATION OF METHODOLOGY OF THE BALANCED SCORECARD SYSTEM FOR QUALITY EVALUATION OF A STRATEGIC BUSINESS UNIT}

\begin{abstract}
The current organizations are charged to have the domain of the technology, to possess quality proven for the world-wide standards and to be enterprises that take care of to the always changeable expectations of the customers, each time more demanding. To survive in this competitive environment it is necessary that they develop tools capable to define its position front to the market, its internal processes front to its proper objectives and its prospection for the future. Such tools must be capable to identify its strong and weak points, in order to provide of its position and definition of the best way to be followed, same that this represents the total change of direction. The objective of this work is to analyze and to describe the stages for the development of integrated and based in the global strategy of the company, as methodology of the Balanced Scorecard, pointers of performance in the sustentabilidade of the organization, and in reaching the goals previously established by the corporative administration. The present research uses of bibliographical data of the referring subjects the corporative administration. With the use of the study of documentary case as research method it is concluded that the performance pointers are vital tools when structuralized in order to take care of the financial perspectives, of the customers, the internal processes and the learning and growth of the organization.
\end{abstract}

Keywords: Corporative Administration; Pointers of Performance; Balanced Scorecard.

Revista Ibero-Americana de Estratégia - RIAE, São Paulo, v. 9, n. 3, p. 139-173, set./dez. 2010. 
APLICACIÓN DE LA METODOLOGÍA DEL SISTEMA DE EVALUACIÓN CUADRO DE MANDO PARA LA CALIDAD DE UNA UNIDAD ESTRATÉGICA DE NEGOCIOS

\section{RESUMEN}

Actualmente, las organizaciones pagan por tener el campo de la tecnología, han demostrado con los estándares mundiales y que las empresas que cumplan las expectativas de los clientes en constante cambio, más exigente. Para sobrevivir en este entorno competitivo, es necesario desarrollar herramientas capaces de definir su posición ante el mercado, los procesos internos con respecto a sus propias metas y sus perspectivas para el futuro. Estas herramientas deben ser capaces de identificar sus fortalezas y debilidades con el fin de promover el fortalecimiento de su posición y definir el mejor camino a seguir, aunque esto representa un cambio total de dirección. El objetivo de este estudio es analizar y describir los pasos para la elaboración de indicadores de rendimiento basados en la estrategia integrada y global de la empresa, como la metodología Balanced Scorecard, se centró en la sostenibilidad de la organización, y alcanzar los objetivos previamente establecidos por la dirección corporativa. Esta investigación hace uso de los datos bibliográficos de temas relativos a Gobierno Corporativo, Control y Medición del Desempeño Modelos de indicadores de rendimiento. Con el documento de estudio de caso como método de investigación se concluye que los indicadores de desempeño son herramientas vitales cuando estructurado para satisfacer las perspectivas financieras, clientes, procesos internos y aprendizaje y crecimiento de la organización.

Palabras-clave: Gobierno Corporativo; Indicadores de Rendimiento; Balanced Scorecard. 


\section{INTRODUÇÃO}

O campo da administração em nossa época está passando por uma verdadeira revolução devido às rápidas mudanças no contexto mundial. As organizações públicas e privadas atuais necessitam constantemente se adaptar as novas exigências do mercado se quiserem sobreviver e prosperar em um novo local de trabalho dirigido pela tecnologia (Daft, 2005).

As organizações estão procurando desenvolver estratégias que interajam com os fatores do ambiente empresarial, a fim de otimizar o processo administrativo, detectar as mudanças de mercado e suas respectivas implicações para o negócio e tomar decisões acertadas e oportunas. Surgem, então, novas formas de condução do negócio; a empresa se diversifica em Unidades Estratégicas de Negócios (UEN), organizações preparadas para atingir mercados específicos de forma individualizada. Nasce, assim a Administração Corporativa como uma filosofia de estruturação da empresa, responsável pela consolidação dos negócios.

Em resposta a essas alterações na forma de administrar é fundamental que as organizações estabeleçam uma hierarquia das ações que devem ser tomadas para o melhor acompanhamento dos negócios.

A função Controle torna-se fator crítico a ser desenvolvido para a análise e avaliação da estratégia e do desempenho empresarial, dessa forma, os indicadores de desempenho de forma evolutiva estão sendo aplicados como uma ferramenta de gestão que, quando bem estruturada e desenvolvida, além de aferir os resultados da organização auxiliam na implementação da estratégia empresarial, pois no momento de sua averiguação gera a seus gestores subsídios à arbitragem das alternativas existentes, gerando, assim, conhecimentos que resultam na aprendizagem organizacional.

Diante da percepção de uma aparente dificuldade sistêmica das organizações em definirem indicadores de desempenho corporativos que possam ser cascateados a fim de integrar as várias dimensões de controle, o Balanced Scorecard (BSC) surge como um tipo de ferramenta de mensuração indispensável à tomada de decisão destacando-se, em relação aos demais modelos de medição de desempenho existentes, quando o objetivo é atingir metas estabelecidas pela alta administração na definição da estratégia.

Assim, o objetivo geral desta pesquisa é analisar e descrever as etapas para o desenvolvimento de indicadores de desempenho integrados e baseados na estratégia global da empresa, conforme metodologia do Balanced Scorecard, focados na sustentabilidade da organização, e em atingir as metas previamente estabelecidas pela administração corporativa.

Revista Ibero-Americana de Estratégia - RIAE, São Paulo, v. 9, n. 3, p. 139-173, set./dez. 2010. 


\section{REVISÃO TEÓRICA}

Neste item serão apresentados o histórico, os principais conceitos e as perspectivas do Balanced Scorecard, desenvolvido por Robert Kaplan e David Norton, impulsionados pelas limitações dos tradicionais sistemas de medição existentes até a época. O surgimento do BSC remonta-se a 1990, quando o Instituto Nolan Norton, unidade de pesquisa da KPMG, tinha como principal executivo David Norton, responsável pela liderança de um projeto de pesquisa, juntamente com o consultor acadêmico Robert Kaplan.

$\mathrm{O}$ estudo fora denominado Measuring Performance in the Organization of the Future, e foi realizado entre várias empresas de manufatura e serviços da indústria pesada e de alta tecnologia. Tinha como objetivo desenvolver um novo modelo de medição do desempenho organizacional capaz de suprir as deficiências dos antigos modelos.

Acreditava-se que os métodos de avaliação do desempenho empresarial existentes até o momento, baseados somente em dados financeiros, estavam se tornando obsoletos e prejudicando a criação de valor para as empresas. Segundo Kaplan e Norton (2004):

Acreditávamos, na época, que os ativos baseados no conhecimento - sobretudo os colaborados e tecnologia da informação - tornavam-se cada vez mais importantes para o sucesso competitivo das empresas. Mas o principal sistema de avaliação das empresas ainda era o da contabilidade financeira, que tratava como despesas do período em que foram efetuados todos os investimentos em capacidades dos empregados, em bancos de dados, em sistemas de informação, em relacionamentos com os clientes, em qualidade, em processos responsivos e em produtos e serviços inovadores. Os relatórios financeiros tradicionais não forneciam fundamentos para a mensuração e gestão do valor criado pelo aumento das habilidades dos ativos intangíveis da organização (p. 12).

Os autores afirmam que não era possível gerenciar eficazmente o que não era medido e que os executivos e funcionários das organizações tinham o costume de controlar unicamente o que era medido, e, por a esse motivo, acompanhavam de perto apenas os indicadores financeiros de curto prazo existentes até o momento, não se dedicando ao gerenciamento dos ativos intangíveis, responsáveis por garantir o sucesso financeiro no futuro.

A conclusão do estudo, conforme apresenta Kaplan e Norton (1997), foi o desenvolvimento do Balanced Scorecard organizado a partir de quatro perspectivas complementares e distintas que se equilibram entre os objetivos de curto e longo prazos, de medidas financeiras e não financeiras, de indicadores de tendência e ocorrência e de perspectivas internas e externas, são elas: a perspectiva financeira, do cliente, interna e da inovação e aprendizado.

Revista Ibero-Americana de Estratégia - RIAE, São Paulo, v. 9, n. 3, p. 139-173, set./dez. 2010. 


\subsection{A EVOLUÇÃO DO BALANCED SCORECARD}

O Balanced Scorecard não mantém uma mesma definição desde o seu surgimento. A evolução do estudo pode ser verificada na sequiência de quatro artigos, todos publicados pela Harvard Business Review, e em três livros publicados por Boston: Harvard Business School Press:

- No primeiro artigo, publicado em janeiro-fevereiro de 1992 The Balanced Scorecard: Measures that Drive Performance, foi resultado da pesquisa inicial de um ano de estudo em 1990. Apresenta o conceito de um sistema balanceado de mensurações e recomenda que as organizações mantenham em uso os indicadores financeiros existentes, e, juntamente com estes, criem indicadores não-financeiros que representem as perspectivas dos clientes, processos internos e da aprendizagem e crescimento (Boffi, 2007).

A publicação desse artigo foi o marco inicial na alteração do sistema de avaliação do desempenho, até então dominado pelos relatórios financeiros tradicionais, limitados apenas à contabilidade financeira que considerava os investimentos nos colaboradores, em tecnologia, na qualidade e em processos como despesas do período. Kaplan e Norton (2004) observaram que as organizações estavam aprovando o Balanced Scorecard como uma ferramenta abrangente de avaliação do desempenho, contudo, também puderam perceber que os executivos já almejavam utilizá-lo na implementação de novas estratégias.

Essa alteração deu-se, principalmente, devido ao deslocamento da criação de valor dos ativos tangíveis para os intangíveis, no mercado das empresas industriais, deixando de ser apenas recursos de produção, e nas características dos produtos, para oferecer valor aos clientes-alvo (Kaplan \& Norton, 2004).

- No segundo artigo, publicado em setembro-outubro de 1993 Putting the Balanced Scorecard to Work, Kaplan e Norton descrevem os elementos de um novo sistema de gestão da estratégia (Boffi, 2007);

Revista Ibero-Americana de Estratégia - RIAE, São Paulo, v. 9, n. 3, p. 139-173, set./dez. 2010. 
Sandra Aparecida Nogueira de Oliveira Boffi, Edson Aparecida de Araújo Querido Oliveira, Monica Franchi Carnielo \& Vilma da Silva Santos

- No terceiro artigo, publicado em janeiro-fevereiro de 1996 Using the Business Scorecard as a Strategic Management System, os autores apresentaram como os executivos poderiam utilizar o BSC na implantação e acompanhamento da eficácia da estratégia (Boffi, 2007);

- Após o sucesso dos três primeiros artigos e atendendo a constantes solicitações de maiores informações e detalhes da aplicação do Balanced Scorecard, os autores publicaram, em 1996, o primeiro livro The Balanced Scorecard: Translating Strategy into Action, trabalhando o BSC em duas partes: na primeira descrevem como o BSC podia atuar na medição da estratégia e na segunda parte apresentam o BSC como ferramenta de gestão da estratégia (Boffi, 2007);

- No segundo livro, publicado em 2001, The Strategy-Focused Organization: How Balanced Scorecard Companies Thrive in the New Business Environment, os autores ampliaram os conceitos apresentados na segunda parte do livro anterior, referente à gestão da estratégia e apresentaram o resultado de uma pesquisa, feita em várias empresas, sobre a utilização do BSC para nortear as organizações para a estratégia (Boffi, 2007);

- No quarto artigo, publicado em janeiro-fevereiro de 2001, Having Trouble with Your Strategy? Then Map It, Kaplan e Norton propunham um modelo de mapa estratégico básico que poderia ser utilizado em qualquer tipo de organização ou atividade, capaz de traduzir a estratégia em termos operacionais (Boffi, 2007); e

- No terceiro livro, publicado em 2004, Strategy Maps, os autores mostraram como os mapas estratégicos deveriam ser utilizados pelas organizações para visualizarem a estratégia (Boffi, 2007).

Como visto, essa ferramenta sofreu várias alterações desde a sua criação; os autores interpretam as mudanças como constantes adaptações às necessidades das organizações, como evolução da sua forma de operação e alto nível de abertura em sua utilização.

Para Kallás (2003, p. 25), esta ausência de rigor dos autores Robert Kaplan e David Norton, quando classificam o conceito do Balanced Scorecard, tem a intenção de "deixar o texto 
Aplicação da Metodologia do Balanced Scorecard no Sistema de Avaliação da Qualidade de uma Unidade Estratégica de Negócios

mais leve para a leitura", tornando possível, então, encontrar diversas classificações como: modelo, sistema, instrumento e ferramenta.O autor afirma que a evolução e o uso do Balanced Scorecard fizeram com que se tornasse uma importante ferramenta de gestão estratégica.

Em resumo, após cada publicação é possível visualizar os complementares desdobramentos e aplicações do Balanced Scorecard. Em 1992 e 1993 foi entendido como sistema balanceado de mensuração do desempenho; ainda em 1993 abordou-se a respeito de sua concentração na estratégia da empresa, que, conforme Kaplan e Norton (2004), é o fator mais importante a ser implementado pela organização. Em 1996 foi descrito como um novo sistema de gestão do desempenho estratégico; em 2000, como um sistema de gestão da estratégia.

\subsection{CONCEITUANDO O BALANCED SCORECARD}

Conforme apresenta Telles (2003, p. 215), o Balanced Scorecard surge como "uma proposta de abordagem estruturada para a construção de indicadores, baseada numa perspectiva de negócio constituída por dimensões independentes, mas interagentes para o resultado de uma organização”.

Lawton (2002) sintetiza que o Balanced Scorecard tem a intenção de proporcionar uma ligação entre a estratégia da empresa e os indicadores operacionais de performance. Os objetivos e as medidas do Balanced Scorecard são derivados de um processo hierárquico (top-down) da missão e da estratégia da organização, por isso conseguem traduzir a missão e a estratégia em objetivos e medidas tangíveis.

Nesse processo as medidas representam o equilíbrio entre os diversos indicadores externos que representam os clientes e acionistas e os indicadores internos - referentes aos processos internos, à inovação e ao aprendizado.

Para Kaplan e Norton (1997), o scorecard busca sustentar-se entre medidas de fácil quantificação e outras subjetivas. Os objetivos e as medidas são responsáveis por focalizar o desempenho organizacional sob quatro perspectivas: financeira, do cliente, dos processos internos e de aprendizado e crescimento e têm como objetivo administrar a estratégia em logo prazo, funcionando como um sistema de gestão estratégica e viabilizando processos gerenciais.

O Balanced Scorecard é um conjunto de indicadores dispostos em quatro distintas e complementares perspectivas: financeira, dos Clientes, dos processos internos e aprendizagem e crescimento.

As perspectivas do Balanced Scorecard, segundo Kaplan e Norton (2004, p. 9), buscam respostas para quatro perguntas, cada qual representando uma vertente distinta. São elas:

Revista Ibero-Americana de Estratégia - RIAE, São Paulo, v. 9, n. 3, p. 139-173, set./dez. 2010. 
Sandra Aparecida Nogueira de Oliveira Boffi, Edson Aparecida de Araújo Querido Oliveira, Monica Franchi Carnielo \& Vilma da Silva Santos

- Como os consumidores nos vêem? (perspectiva do consumidor);

- Em que devemos ser excelentes? (perspectiva dos processos internos);

- Como seremos capazes de continuar melhorando e criando valor? (perspectiva da aprendizagem e crescimento); e

- Como pareceremos para os acionistas? (perspectiva financeira).

\section{METODOLOGIA DA PESQUISA}

Nesse cenário, esta pesquisa destina-se a apresentar a importância da escolha de uma ferramenta de medição ampla, que mapeie a organização como um todo. A aplicabilidade do BSC será investigada por meio da utilização de um estudo de caso exploratório referente à utilização de um sistema de indicadores de desempenho em uma empresa multinacional localizada do Estado de São Paulo, na região do Vale do Paraíba, visando dar uma contribuição às organizações na implantação de um sistema de medição de desempenho.

A unidade de análise é o departamento da Qualidade de uma (UEN) e este trabalho propõese a investigar, por meio de amostra não probabilística por acessibilidade ou conglomerado, como este define, escolhe, implementa e mantém o sistema de medição de desempenho, verificando, também, se esse sistema é capaz de mostrar o resultado obtido até o momento da análise e as tendências de resultado futuro, a fim de proporcionar ao gestor a oportunidade de manter ou alterar os processos conforme objetivos da missão da empresa a serem alcançados.

Busca-se, com a utilização do estudo de caso, analisar um exemplo prático de utilização de indicadores de desempenho que se adapte às necessidades da estrutura local e aos objetivos do negócio em âmbito global, comparando os indicadores de desempenho encontrados no departamento da Qualidade da empresa foco do estudo com a metodologia do Balanced Scorecard.

Esta pesquisa utilizou-se das seguintes fontes de dados: documentação, pesquisada em relatórios escritos, documentos administrativos, atas de reuniões e registros em arquivo resultantes de registros operacionais, como tabelas e gráficos.

Revista Ibero-Americana de Estratégia - RIAE, São Paulo, v. 9, n. 3, p. 139-173, set./dez. 2010. 


\section{ANÁLISE E DISCUSSÃo DOS RESULTADOS}

A UEN foco da pesquisa possui uma estrutura matricial, e seus profissionais estão dispostos de maneira funcional. Está dividida internamente em oito departamentos, denominados Superintendências, de Suprimentos, Qualidade, Engenharia, Planejamento, Gerência de Projetos, Manufatura, Controladoria e de Montagem Externa ou Montagem do equipamento na obra.

Devido ao tipo de produtos e serviços que produz e executa, a empresa é operacionalizada por projetos, o que significa que a cada nova venda é desenvolvido, fabricado e montado um equipamento e/ou serviço diferenciado e específico, que atenda às diferentes necessidades do local onde o equipamento ou serviço é solicitado.

Esse tipo de atuação exige que a organização desenvolva alto nível de tecnologia para atender às características únicas de cada projeto. No caso específico desta empresa, alguns dos exemplos que se destacam são: tipo de solo (unido, arenoso, irregular, entre outros), existência de abalos sísmicos, ambientes de alta corrosividade, submersos e grandes ou pequenos espaços físicos, entre outros.

\subsection{CONSIDERAÇÕES RELACIONADAS Á METODOLOGIA DA ANÁLISE DE DESEMPENHO DA QUALIDADE}

A metodologia do BSC busca o sentido top-down, pois se destina a descrever e comunicar a estratégia do mais alto nível da organização até a execução do trabalho, porém, os autores também afirmam, em todas as suas publicações, a versatilidade do sistema na adaptação às necessidades particulares de cada organização.

Portanto, entende-se que o BSC é uma ferramenta ampla que pode ser utilizada pela Administração Corporativa para a análise de suas respectivas UENs, mas, também, pode ser utilizada pela diretoria de cada UEN na elaboração de suas estratégias e pelos seus departamentos em seus controles gerenciais.

Desse modo, parte-se do pressuposto que cada departamento deve iniciar uma análise de seu atual sistema de medição e providenciar melhorias, quando aplicável para a definição de indicadores de desempenho balanceados, conforme metodologia do BSC.

Revista Ibero-Americana de Estratégia - RIAE, São Paulo, v. 9, n. 3, p. 139-173, set./dez. 2010. 


\subsection{O SISTEMA DE MÉTRICAS DA QUALIDADE}

A área da Qualidade, quanto à realização de suas atividades internas, está estruturado em duas subáreas complementares: a Garantia da Qualidade e a Engenharia da Qualidade. A Garantia da Qualidade é responsável pela interface entre a empresa e o cliente e sua função é assegurar a garantia dos produtos os serviços especificados pelo cliente.

A Engenharia da Qualidade é responsável pelo controle de qualidade durante a fase de manufatura ou subcontratação. O departamento da Qualidade atua a fim de executar a medição e monitoramento dos produtos e serviços oferecidos pela organização, efetuando os acompanhamentos e testes necessários para garantir resultados satisfatórios nas fases de recebimento e aprovação dos materiais e matérias-primas, durante e no final do processo de fabricação, na expedição e nos fornecedores.

O planejamento de suas atividades é feito com a utilização dos seguintes documentos: o Plano de Qualidade, o Plano de Inspeção e Testes e Ordem de Produção ou Instrução de Fornecimento. Em caso de medição e monitoramento dos produtos e serviços na obra são elaborados Manuais de Montagem e Comissionamento.

Durante o ano da aplicação da pesquisa, a área da Qualidade utilizou seis indicadores, todos representados em formas gráficas e nomeados conforme a seguir: I1 - Indicador de Eficiência da Engenharia da Qualidade, I2 - Indicador de Eficiência da Inspeção Externa, I3 - Indicador de Eficácia da Engenharia da Qualidade, I4 - Indicador de Eficiência da Metrologia, I5 - Indicador de Eficiência do Laboratório e I6 - Indicador de Eficiência da Garantia da Qualidade.

\subsubsection{MODELO I1 - INDICADOR DE EFICIÊNCIA DA ENGENHARIA DA QUALIDADE}

Sua função é analisar a eficiência da área de Engenharia da Qualidade em relação à realização da quantidade de horas produtivas trabalhadas no período analisado. Para cada equipamento vendido, dependendo do seu nível de complexidade, é estabelecida uma quantidade de horas a serem gastas com inspeções de qualidade.

A sua função é garantir que o equipamento está em conformidade com os requisitos técnicos especificados pelo cliente no contrato estabelecido entre as partes e garantir os níveis de qualidade necessários para liberação da entrega do produto.

A empresa, para identificar e quantificar os gastos realizados com inspeções optou por caracterizá-las em dois tipos de inspeções de qualidade, em que cada uma é analisada individualmente devido as suas particularidade: a inspeção interna e a inspeção externa.

Revista Ibero-Americana de Estratégia - RIAE, São Paulo, v. 9, n. 3, p. 139-173, set./dez. 2010. 
A primeira é realizada dentro da planta da empresa durante o processo de fabricação do produto, pelo departamento de manufatura da organização, e a outra é a inspeção externa, que é realizada durante o processo de fabricação do produto na empresa subcontratada para o trabalho.

A fim de proporcionar contenção de custos, as inspeções internas, por serem as mais freqüentes, são feitas quase em sua totalidade por funcionários treinados da própria organização, enquanto as inspeções externas são comumente executadas por inspetores contratados, cujos pagamentos são relativos à quantidade de inspeções realizadas no período combinado.

A inspeção externa é necessária quando por decisão estratégica a organização opta por subcontratar a fabricação de partes do produto ou equipamento de um fornecedor devidamente aprovado. Embora o material possa ser de fabricação de terceiros, eles precisam ter a aprovação e garantia da organização:

- Descrição Sumária - o indicador de desempenho utilizado para a análise do andamento da inspeção interna é nomeado Indicador de medição da eficiência da Engenharia de qualidade;

- Identificação da unidade de medida - quantidade de horas produtivas utilizadas pelos funcionários durante o processo de inspeção, quantidade de horas improdutivas e o custo do departamento para a organização. Caracterizam-se como horas produtivas às horas-homem realizadas efetivamente em cada inspeção, e como horas improdutivas às horas-homem utilizadas pelos funcionários em atividades diversas inerentes à profissão, mas não vinculadas diretamente à execução de inspeções, como horas gastas em treinamento, reuniões, palestras e planejamento, entre outras. Este modelo pode ser observado na Figura 1;

Revista Ibero-Americana de Estratégia - RIAE, São Paulo, v. 9, n. 3, p. 139-173, set./dez. 2010. 
Sandra Aparecida Nogueira de Oliveira Boffi, Edson Aparecida de Araújo Querido Oliveira, Monica Franchi Carnielo \& Vilma da Silva Santos

Figura 1 - Indicador de Eficiência da Engenharia da Qualidade.

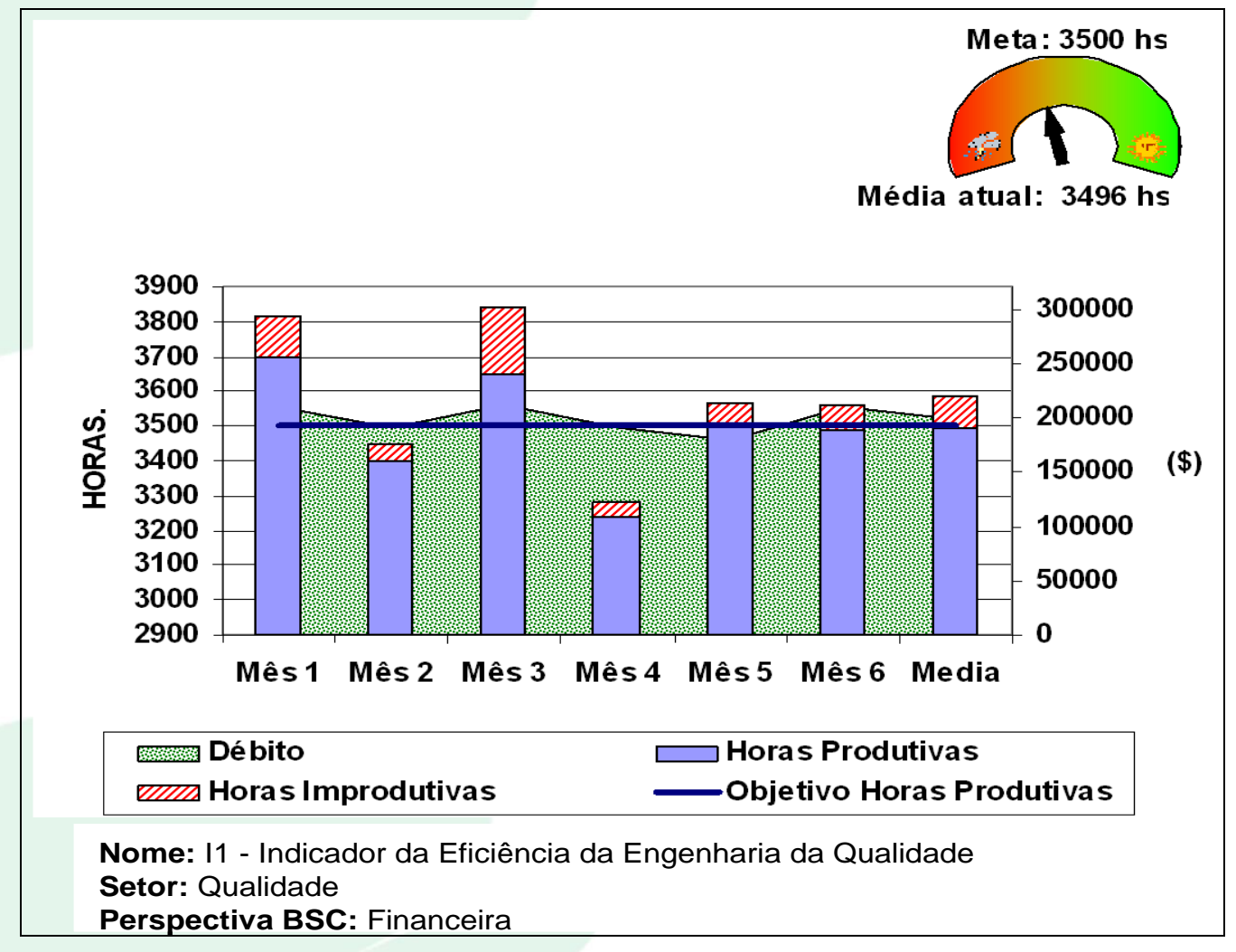

Fonte: Elaborado pelos autores.

- Definição do objetivo do indicador - verificar se a quantidade de horas gastas de forma produtiva estão conforme cronograma estabelecido e se são suficientes para pagar os custos que o departamento representa para a unidade de negócio. Seu objetivo secundário é analisar a quantidade de horas improdutivas realizadas no período em questão;

- Classificação com a perspectiva do BSC - financeira;

- Estabelecimento de metas - 100\% de realização conforme planejado;

- Metodologia do indicador - analisar a diferença entre a quantidade de horas produtivas realizadas pela engenharia da qualidade e as horas planejadas, ou necessárias mensais para a eficiência do departamento e a medição das horas improdutivas, conforme Equação 1;

Revista Ibero-Americana de Estratégia - RIAE, São Paulo, v. 9, n. 3, p. 139-173, set./dez. 2010. 


$$
\text { I1 }=\frac{\text { Quantidade de Horas } \text { Produtivas }}{\text { Quantidade de Horas Planejadas }} \quad \text { Equação } 1
$$

- Periodicidade - mensal.

\subsubsection{MODELO I2 - INDICADOR DE EFICIÊNCIA DA INSPEÇÃO EXTERNA}

Sua função é verificar o valor médio gasto em inspeções externas produtivas realizadas pela área nos sub-fornecedores:

- Descrição Sumária - no caso da necessidade de inspeção externa, esta acontece no fornecedor responsável pela fabricação do material subcontratado (parte do produto ou equipamento). O material pode vir a ser subcontratado dependendo da estratégia adotada pela empresa, devido, principalmente, a alguns motivos, tais como: excesso de trabalho na fábrica como um todo ou em algumas de suas etapas (oxicorte, caldeiraria pesada, leve, usinagem, tratamentos térmicos, pintura, entre outros), podendo gerar perdas de prazo; proximidade do fornecedor com a obra, sendo viável em relação ao custo com transporte; menor custo; entre outros. Todos a fim de analisar a melhor logística para a execução dos trabalhos. A inspeção externa pode ser produtiva ou improdutiva; esta definição é necessária para que seja determinada a fonte pagadora das despesas. É caracterizada como produtiva quando o inspetor responsável encontra no fornecedor as condições essenciais para a execução da inspeção de qualidade, como o correto andamento do cronograma, preparação da peça para a análise, entre outros. Neste caso os custos são pagos pela contratante. É improdutiva quando o inspetor é impedido de executar sua função devido a peça ainda não estar disponível para a inspeção, ou quando apresenta não conformidade com o projeto, gerando a necessidade da programação de nova data. Neste caso o fornecedor é responsabilizado pelos custos da ausência da inspeção e quando necessário ocorre a aplicação de multas por prejuízos causados à organização, em caso de comprometimento dos prazos, perda de eventos de pagamento, ou outros danos;

Revista Ibero-Americana de Estratégia - RIAE, São Paulo, v. 9, n. 3, p. 139-173, set./dez. 2010. 
Sandra Aparecida Nogueira de Oliveira Boffi, Edson Aparecida de Araújo Querido Oliveira, Monica Franchi Carnielo \& Vilma da Silva Santos

- Identificação da unidade de medida - valor financeiro gasto em cada inspeção externa produtiva;

- Definição do objetivo do indicador - analisar o valor gasto em inspeções de qualidade, analisar o valor médio e verificar a ocorrência de inspeções improdutivas e necessidade de retrabalho;

- Classificação com a perspectiva do BSC - financeira;

- Estabelecimento de metas - atingir o custo viável estimado pela organização. Esse indicador é apresentado na Figura 2;

Figura 2 - Indicador de Eficiência da Inspeção Externa.

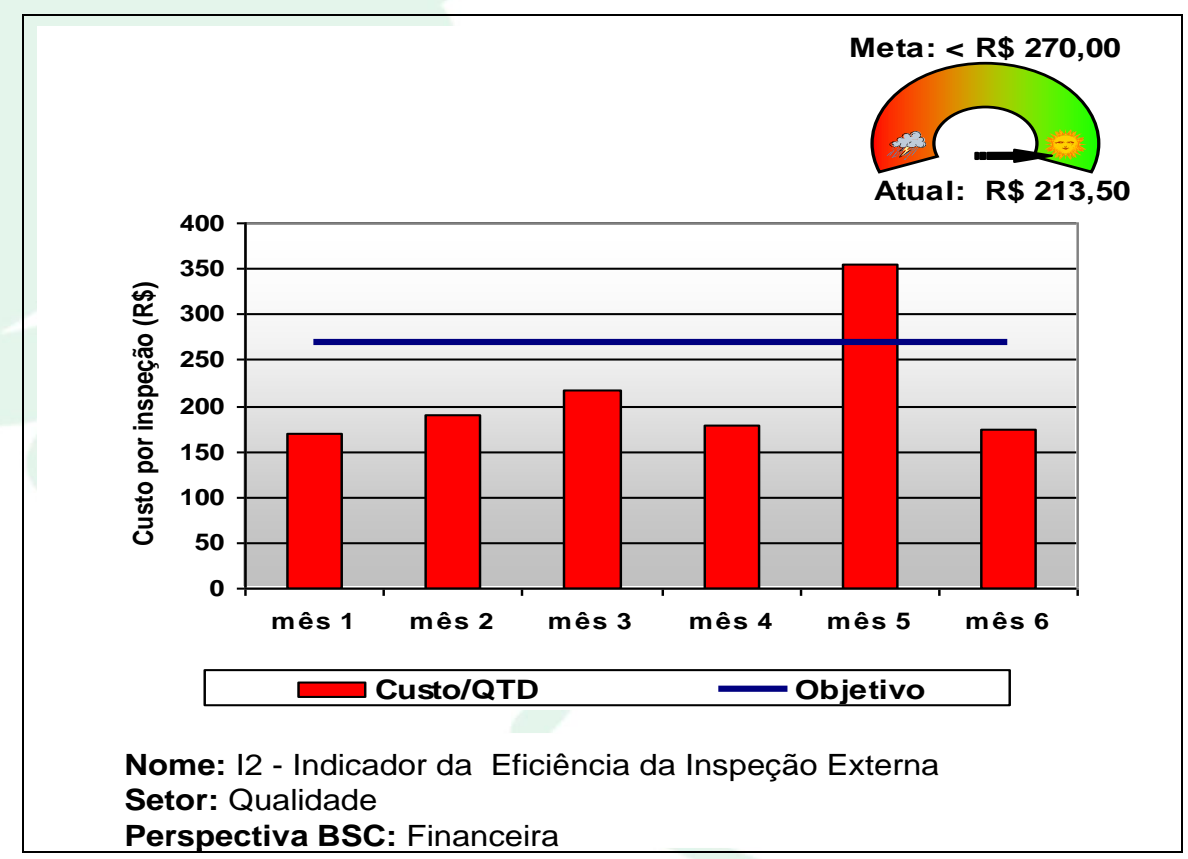

Fonte: Elaborado pelos autores.

- Metodologia do indicador - diferença entre o custo total obtido em cada inspeção em relação à quantidade de inspeções realizadas no período, conforme Equação 2;

$$
\mathrm{I} 2=\frac{\text { CustoTotal em cada Inspeção }}{\text { Quantidadede Inspeções } \operatorname{Re} \text { alizadas }} \text { Equação } 2
$$

- Periodicidade - mensal.

Revista Ibero-Americana de Estratégia - RIAE, São Paulo, v. 9, n. 3, p. 139-173, set./dez. 2010. 


\subsubsection{MODELO I3 - INDICADOR DE EFICÁCIA DA ENGENHARIA DA QUALIDADE}

Sua função é evitar que o equipamento seja entregue para montagem na obra com desvios (não-conformidades) em relação ao especificado no contrato e fora dos padrões de qualidade necessários:

- Descrição Sumária - a liberação da qualidade para encaminhamento à obra dos componentes do produto e do equipamento subcontratado ou fabricado na própria empresa são feitos com a sua aprovação no momento da inspeção de qualidade. As inspeções, tanto internas quanto externas, são realizadas durantes as seguintes fases, de acordo com a necessidade: no recebimento de materiais, durante a fabricação e na expedição do produto para a obra, que visam averiguar se o equipamento está em conformidade com o especificado e pode ser enviado para a obra para sua respectiva montagem. Com a utilização desses pontos de verificação, em caso de ocorrência de desvio, a área faz o registro e inicia um plano de ação para a retificar as nãoconformidades, garantindo que o equipamento somente saía da empresa depois de realizadas as devidas correções. Quando uma não-conformidade é detectada dentro da empresa, os custos do reparo são pontuais, não se tem grande dispêndio monetário e perda de tempo, pois o equipamento pode ser facilmente corrigido, o que somente não é possível caso seja descoberto um grande desvio em sua estrutura. Em contrapartida, se a não conformidade for descoberta somente após entrega na obra tem-se problemas, cuja resolução se torna mais desfavorável para a empresa, pois o custo do reparo é maior devido a algumas especificidades como o elevado custo para o transporte de peças adicionais, ou até mesmo pela necessidade de o equipamento ser corrigido na fábrica para ser retrabalhado e após correções novo transporte de volta, envio de mão-de-obra especializada, supervisão de montagem extra, e, principalmente, o desgaste da imagem da empresa perante o cliente;

- Identificação da unidade de medida - quantidade de não-conformidades detectadas em inspeções internas ou externas durantes as fases de recebimento de materiais, fabricação e expedição do produto e quantidade de não-conformidades detectadas na obra;

Revista Ibero-Americana de Estratégia - RIAE, São Paulo, v. 9, n. 3, p. 139-173, set./dez. 2010. 
Sandra Aparecida Nogueira de Oliveira Boffi, Edson Aparecida de Araújo Querido Oliveira, Monica Franchi Carnielo \& Vilma da Silva Santos

- Definição do objetivo do indicador - este indicador analisa caso a caso todas as nãoconformidades identificadas na obra, com o objetivo de quantificar quais poderiam ter sido evitadas de fossem descobertas antes de seu transporte para a obra, caso tivessem sido detectadas pelos inspetores nas fases de recebimento, inspeção interna, inspeção externa e expedição;

- Classificação com a perspectiva do BSC - aprendizado e crescimento, pois após identificação da fase na qual a inspeção foi falha, visa-se treinar os envolvidos para evitar uma nova ocorrência. O indicador para controle das não-conformidades é mostrado na Figura 3;

Figura 3 - Indicador de Eficácia da Engenharia da Qualidade.

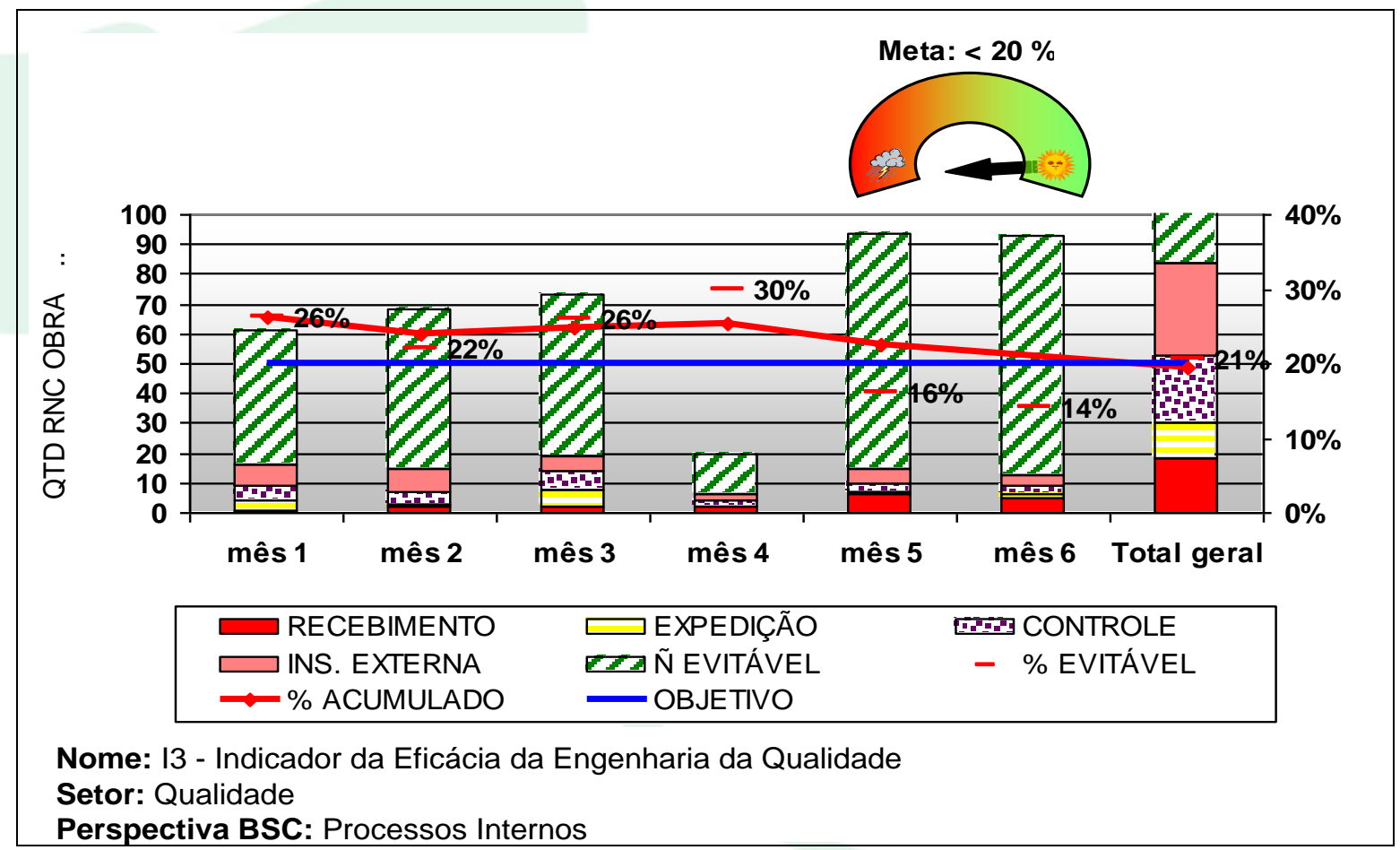

Fonte: Elaborado pelos autores.

- Estabelecimento de metas - é estabelecida pela área durante a análise crítica e objetivos de aprendizagem; 
- Metodologia do indicador - interpretar todas as não-conformidades detectadas na obra, relacionando a quantidade das não-conformidades que poderiam ter sido evitadas antes da entrega do equipamento;

- Um exemplo típico de não-conformidade que não pode ser identificada antecipadamente são as relacionadas com a montagem das partes do equipamento, pois somente ocorrem na obra, ou problemas durante o transporte, como representado na Equação 3;

$$
\text { I3 }=\frac{\text { Quantidade de Não }- \text { Conformidades Evitáveis }}{\text { QuantidadeTotal de Não }- \text { Conformidades }} \quad \text { Equação } 3
$$

- Periodicidade - mensal.

\subsubsection{MODELO I4 - INDICADOR DE EFICIÊNCIA DA METROLOGIA}

Sua função é verificar o nível de atendimento dos prazos estabelecidos para as calibrações dos instrumentos utilizados pelos departamentos da organização, como manufatura, montagem no campo e pelos inspetores de qualidade (ajuste dos equipamentos de medição):

- Descrição Sumária - a organização adota uma norma interna que apresenta as regras para a aferição dos instrumentos. Nela estão estabelecidos a sistemática para a entrega do equipamento na metrologia, o prazo de conclusão dos trabalhos e a forma de empréstimo de instrumentos de terceiros, entre outros. O setor de manufatura necessita ter instrumentos calibrados e certificados em todas as suas fases; é proibido o trabalho com instrumentos com prazos de calibração vencidos. A não calibração do instrumento, bem como o seu atraso, pode implicar em gerar parada na fábrica, causar atrasos, custos extras no aluguel de instrumentos aferidos, erro na medição das peças, comprometimento na montagem do equipamento e perda de tempo para empréstimo de instrumentos de outras áreas. Como por exemplo: o setor de caldeiraria deixa o instrumento para ser calibrado e tem que emprestar o mesmo da área de usinagem, causando o atraso deste setor. Esse modelo de Indicador pode ser observado na Figura 4;

Revista Ibero-Americana de Estratégia - RIAE, São Paulo, v. 9, n. 3, p. 139-173, set./dez. 2010. 
Sandra Aparecida Nogueira de Oliveira Boffi, Edson Aparecida de Araújo Querido Oliveira, Monica Franchi Carnielo \& Vilma da Silva Santos

Figura 4 - Indicador de Eficiência da Metrologia.

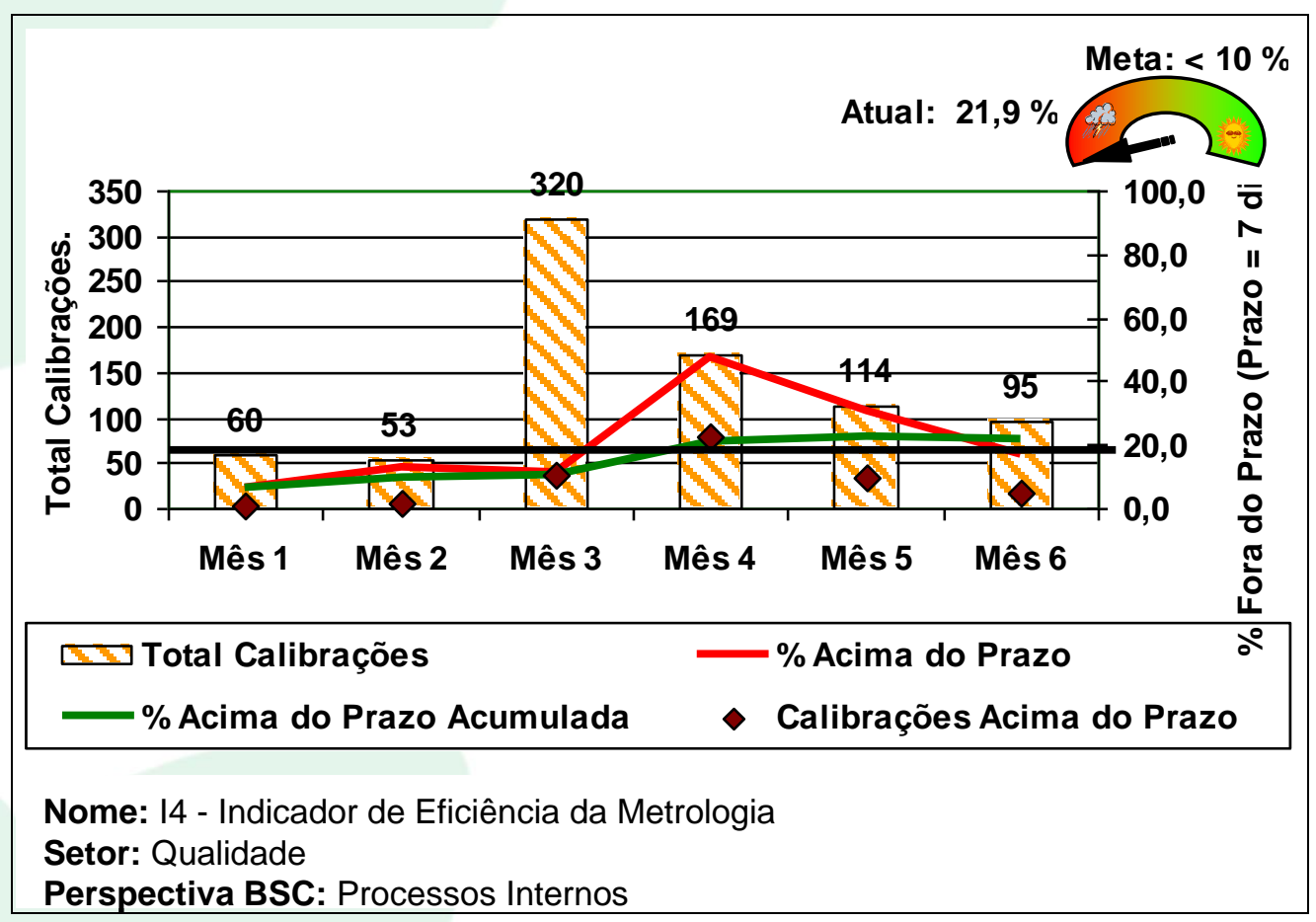

Fonte: Elaborado pelos autores.

- Identificação da unidade de medida - quantidade de calibrações executadas pela área de metrologia;

- Definição do objetivo do indicador - identificar as calibrações realizadas fora do prazo estabelecido e sanar suas causas para evitar que se repitam;

- Correlação com a perspectiva do BSC - processos internos;

- Estabelecimento de metas - é estabelecida pela área durante a análise crítica e objetivos de aprendizagem;

- Metodologia do indicador - é a relação entre a quantidade total de calibrações e as calibrações realizadas fora do prazo, conforme Equação 4;

$$
\text { I4 }=\frac{\text { Quantidade Total de Calibrações Re alizadas }}{\text { Quantidade Total de Calibrações Forado } \operatorname{Pr} a z o} \quad \text { Equação } 4
$$


- Periodicidade - mensal.

\subsubsection{MODELO I5 - INDICADOR DE EFICIÊNCIA DO LABORATÓRIO}

Sua função é medir a quantidade de ensaios mecânicos destrutivos solicitados pelo departamento de manufatura, bem como a quantidade atendida no período solicitado:

- Descrição Sumária - o ensaio destrutivo é um tipo de exame de experiência para a verificação se o material pesquisado atende ao fim que se destina. $\mathrm{Na}$ empresa foco da pesquisa, os ensaios são divididos em três tipos quanto a sua finalidade: um destina-se ao treinamento e aprovação de soldadores, o outro para qualificação dos diferentes tipos de chapas recebidas, caso seja necessário, e o último por solicitação do departamento de montagem externa, quando detectado algum tipo de anomalia ou quebra de parte de equipamento, para a análise do problema. Nesse caso é feito um relatório da análise e encaminhamento à área de engenharia, que será responsável pela entrega do laudo técnico do fato ocorrido sobre as condições do material e da montagem. Quando o ensaio é utilizado para treinamento e certificação dos soldadores da empresa são utilizados pedaços do material, denominados corpos de prova, nos quais são simuladas situações em que são verificados os níveis de atendimento ao especificado. O objetivo principal da utilização de ensaios é para verificar se o material que está sendo analisado está de acordo com o especificado pelo projeto, em quesitos como dureza, resistência do material, tração, dobramento e impacto, entre outros. A utilização de ensaios na empresa é necessária quando, por razões estratégicas, as chapas são adquiridas sem o certificado de sua realização, devido à alteração nos projetos ou para tipos específicos de testes;

- Identificação da unidade de medida - quantidade de ensaios solicitados pelas áreas responsáveis e realizados no período;

- Definição do objetivo do indicador - verificar se o laboratório está executando todos os ensaios solicitados dentro do prazo estabelecido; 
Sandra Aparecida Nogueira de Oliveira Boffi, Edson Aparecida de Araújo Querido Oliveira, Monica Franchi Carnielo \& Vilma da Silva Santos

- Classificação com a perspectiva do BSC - processos internos;

- Estabelecimento de metas - $100 \%$ conforme planejado - O modelo de Indicador utilizado para controle dos ensaios pode ser observado na Figura 5;

Figura 5 - Indicador de Eficiência do Laboratório.

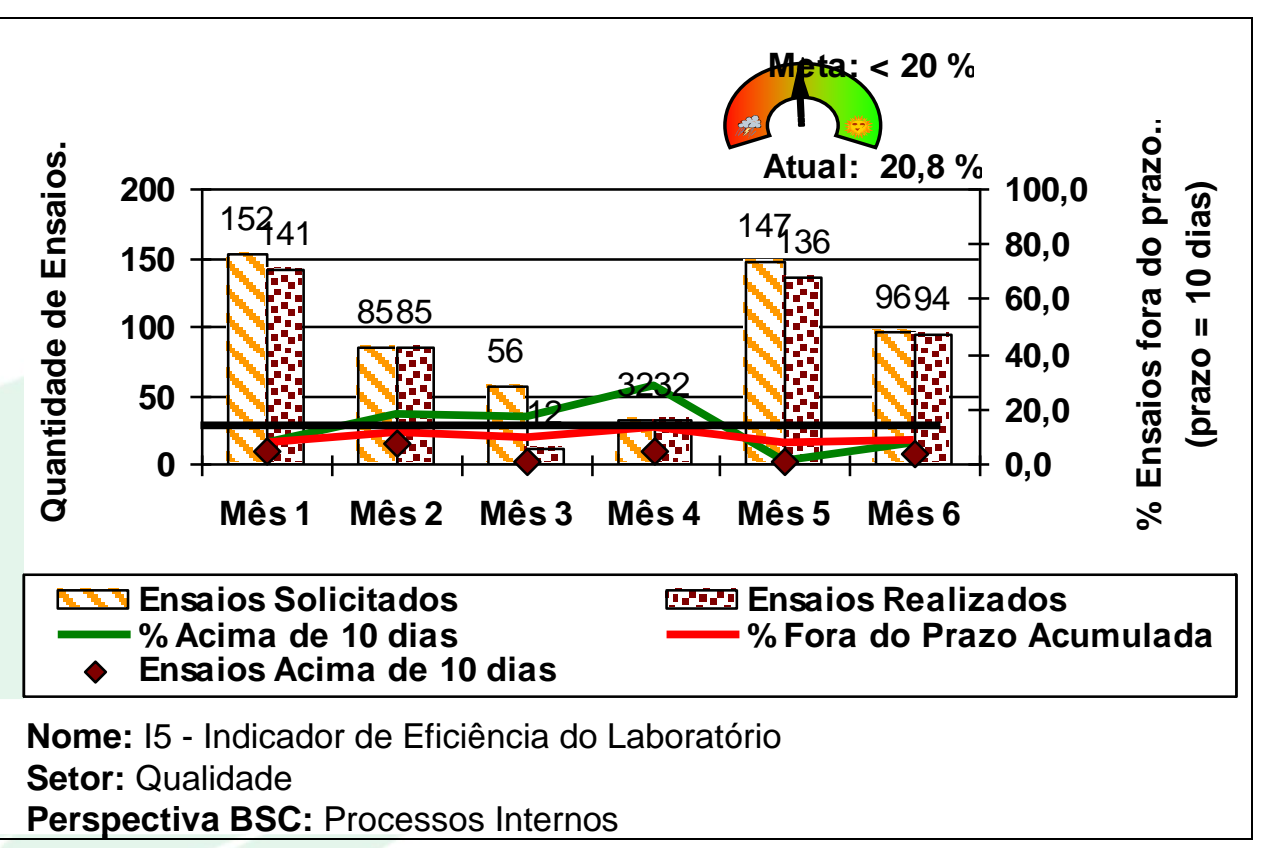

Fonte: Elaborado pelos autores.

- Metodologia do indicador - diferença entre a quantidade de ensaios solicitados e realizados, conforme Equação 5;

I5 = Quantidade de Ensaios Solicitados $\quad$ Equação 5

Periodicidade - mensal.

\subsubsection{MODELO I6 - INDICADOR DE EFICIÊNCIA GARANTIA DA QUALIDADE}

Sua função é analisar a quantidade de horas produtivas, ou seja trabalhadas em projetos pela equipe no período da análise:

Revista Ibero-Americana de Estratégia - RIAE, São Paulo, v. 9, n. 3, p. 139-173, set./dez. 2010. 
- Descrição Sumária - a garantia da qualidade é responsável pela interface entre a empresa e o cliente, a fim de assegurar que o projeto está sendo desenvolvido conforme o especificado e dentro dos padrões de qualidade. É o departamento que gerencia a certificação de qualidade da unidade de negócio, como: ISO 9001, ISO 14001, entre outras, e acompanha a aplicação dos itens das normas nas áreas da empresa;

- Identificação da unidade de medida - quantidade de horas produtivas e improdutivas realizadas no período;

- Definição do objetivo do indicador - verificar se as quantidades de horas gastam de forma produtiva estão conforme cronograma estabelecido e são suficientes para pagar os custos que o departamento representa para a unidade de negócio. Seu objetivo secundário é analisar a quantidade de horas improdutivas realizadas no período em questão. Esse modelo de Indicador pode ser observado na Figura 6.

Figura 6 - Indicador de Eficiência da Garantia da Qualidade.

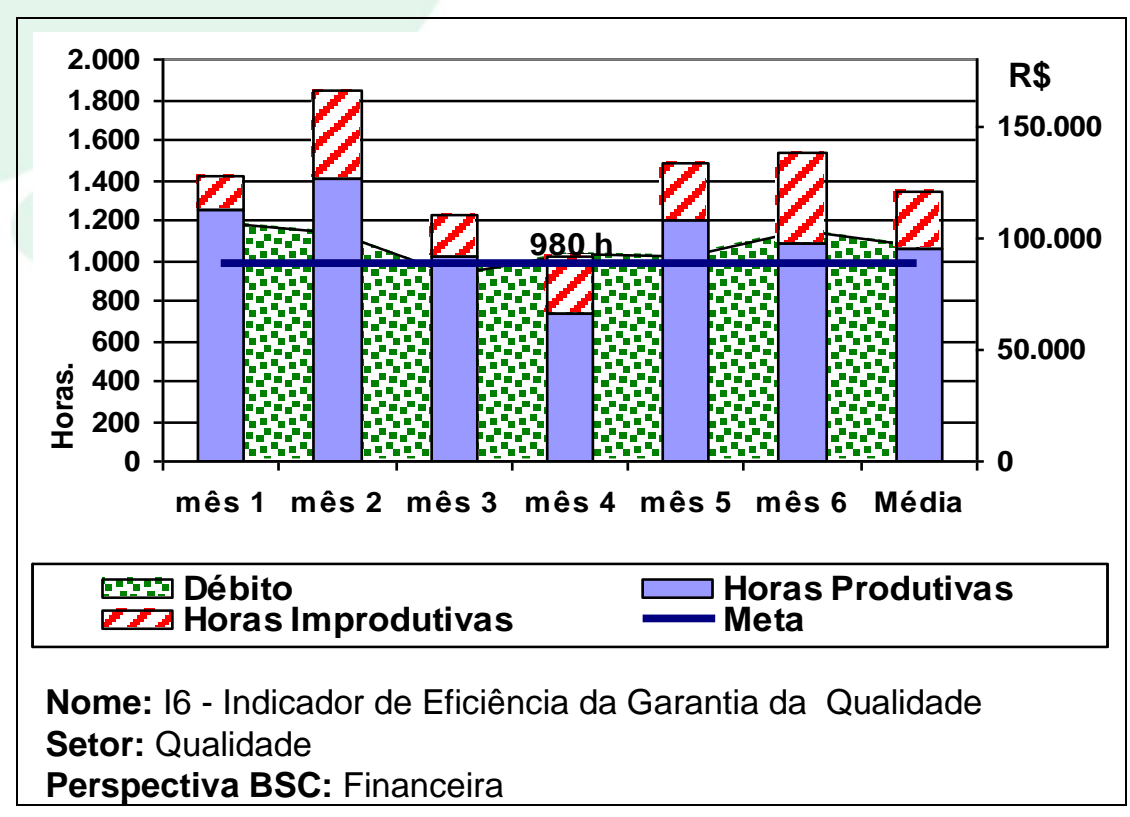

Fonte: Elaborado pelos autores.

- Periodicidade - mensal.

Revista Ibero-Americana de Estratégia - RIAE, São Paulo, v. 9, n. 3, p. 139-173, set./dez. 2010. 
Sandra Aparecida Nogueira de Oliveira Boffi, Edson Aparecida de Araújo Querido Oliveira, Monica Franchi Carnielo \& Vilma da Silva Santos

- Correlação com a perspectiva do BSC - financeira.

- Estabelecimento de metas - $100 \%$ de realização conforme planejado.

- Metodologia do indicador - diferença entre a quantidade de horas produtivas e as horas planejadas, ou necessárias mensais e a medição das horas improdutivas, conforme Equação 6.

$$
\text { I6 }=\frac{\text { Quantidade de Horas Produtivas }}{\text { Quantidade de Horas Planejadas }} \quad \text { Equação } 6
$$

\subsection{ANÁLISE DO SISTEMA DE MÉTRICAS DA QUALIDADE}

Para melhor entendimento do sistema de medição atual da Qualidade, cada indicador será analisado individualmente, em seguida será apresentado o conjunto de indicadores, sua representatividade para o processo decisório do departamento e as possíveis sugestões de melhorias.

\subsubsection{ANÁLISE DO INDICADOR I1}

Este modelo, embora seja nomeado como Indicador de Eficiência da Engenharia da Qualidade, tem a função somente de verificar se a quantidade de horas produtivas (ou seja, executadas em projetos) pela área da engenharia da qualidade está de acordo com a quantidade necessária para o seu pagamento, ou seja, se o departamento está executando as horas produtivas cabíveis.

Diz-se que as horas produtivas pagam um determinado departamento, pois conforme a estrutura da empresa, em todo início de ano fiscal é elaborado um Budget, tipo de orçamento que calcula o valor operacional do respectivo departamento para a organização.

Por exemplo, se um departamento possui 50 funcionários, o gasto para sua utilização com salários, encargos sociais, manutenção predial, equipamentos, softwares, entre outros, anual é de R\$ 3.000.000; logo, o departamento custa mensalmente para a organização à quantia de R $\$ 250.000$ e o valor hora-homem (considerando a média mensal de 180 horas) é de $\mathrm{R} \$ 27,80$. Como a empresa é paga por projetos, é necessário serem trabalhadas em média 180 horas-homem mensais para 
Aplicação da Metodologia do Balanced Scorecard no Sistema de Avaliação da Qualidade de uma Unidade Estratégica de Negócios

cumprimento do Budget da área e evitar a subliquidação do departamento, ou seja, que o custo operacional seja mais elevado que o previsto pela organização no início do ano fiscal.

Neste sentido, este indicador, embora necessário para fins gerenciais das análises do departamento como um todo, não calcula a eficiência relacionada ao cumprimento dos prazos e quantidade de horas orçadas por projeto em andamento na área da qualidade.

O departamento da qualidade é produtivo, ou seja, também possui uma quantidade de horas orçadas para cumprimentos de suas atividades. Portanto, sugere-se a utilização de um indicador que verifique a quantidade de horas orçadas e gastas por projetos de um mesmo cliente, com a função de focar área de qualidade para atingir a expectativas dos clientes e não ultrapassar os custos estimados.

Contudo, no caso da área de qualidade a quantidade de horas planejadas para inspeções somente são ultrapassadas se houver a ocorrência de determinado erro em alguma fase anterior, como na fase de projetos, manufatura e montagem na obra, entre outros. Então, a utilização do modelo proposto visa pontuar a conclusão atividades executadas em conformidade com o planejado para cada projeto. A Figura 7 apresenta a respectiva sugestão, é nomeada de Proposta 1 - P1.

Figura 7 - P1 Indicador de Atendimento ao Cliente.

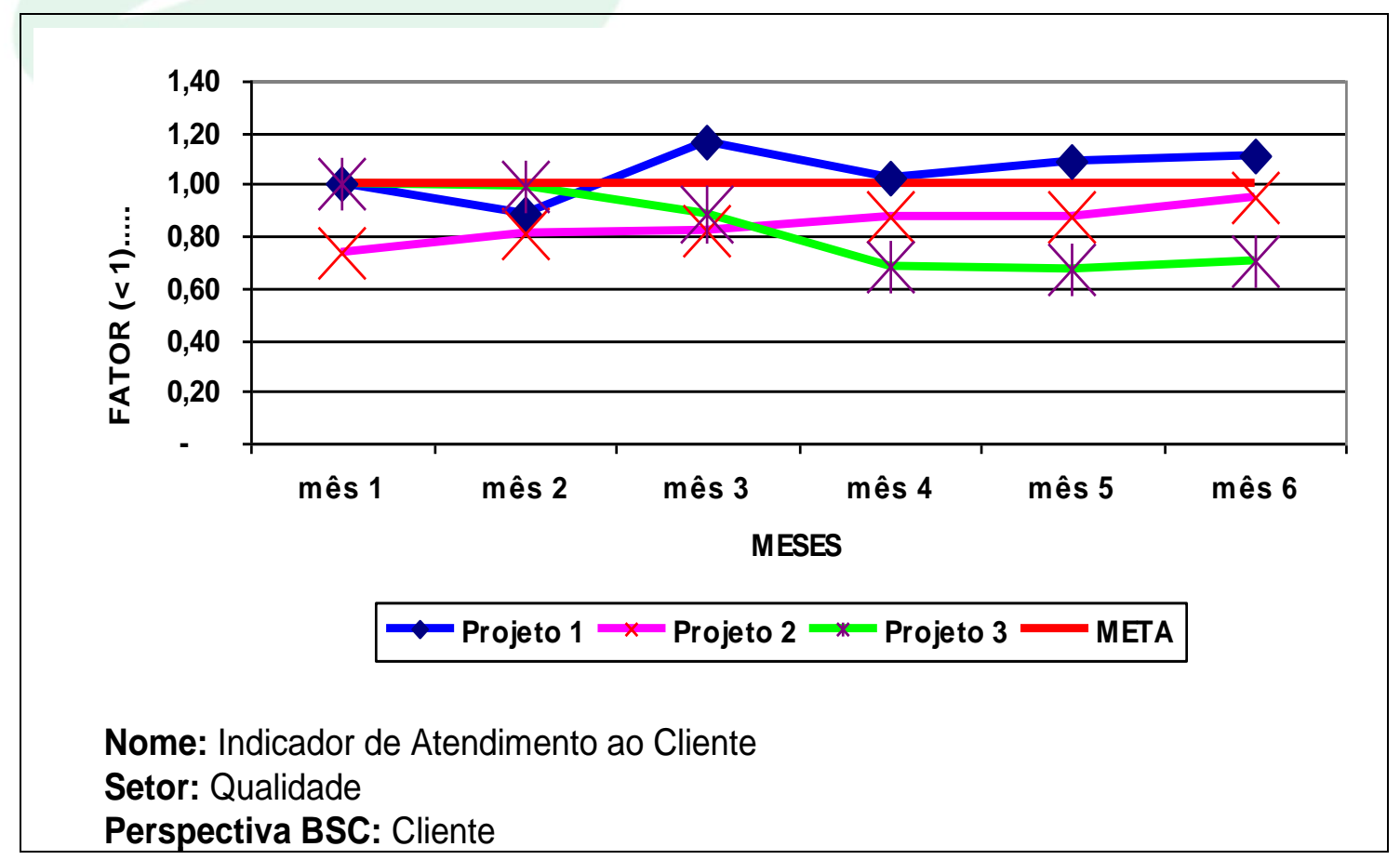

Fonte: Elaborado pelos autores.

Revista Ibero-Americana de Estratégia - RIAE, São Paulo, v. 9, n. 3, p. 139-173, set./dez. 2010. 


\subsubsection{ANÁLISE DO INDICADOR I2}

Este é um indicador de desempenho de função gerencial para controle dos custos logísticos necessários para o processo e execução da inspeção externa, como deslocamento, hospedagem e alimentação do inspetor, verificando o total gasto em cada situação. Sua medição proporciona a possibilidade de algumas economias financeiras locais em relação à definição de uma melhor logística a ser utilizada pelo inspetor contratado na execução de suas atividades. Devido a sua finalidade, não é considerado um indicador de medição estratégica para o departamento, mas essencial para o controle dos gastos, dada a quantidade de inspeções realizadas.

\subsubsection{ANÁLISE DO INDICADOR I3}

Este modelo de indicador objetiva identificar a porcentagem de erros cometidos pela área da engenharia da qualidade na liberação de peças, equipamentos, entre outros, com não conformidades passíveis de serem descobertas internamente, evitando assim maiores custos e desgaste da imagem da empresa frente ao cliente.

Embora o departamento quantifique os erros cometidos e elabore medidas corretivas com o treinamento de sua equipe para não permitir que o mesmo erro de inobservância ocorra, não quantifica a incidência de um mesmo tipo de erro em determinado processo ou equipamento para o treinamento do agente causador, da não-conformidade.

Sugere-se a elaboração de um indicador que verifique os tipos de erros cometidos por tipo de equipamento e agente causador a fim de propiciar os treinamentos necessários para correção do processo errôneo e para o desenvolvimento da melhoria contínua.

Dessa forma, a área de qualidade, além de garantir a conformidade dos equipamentos fabricados, pode auxiliar a organização como agente propulsor de correções em todas as áreas da empresa na busca de melhorias. A Tabela 1 apresenta o modelo proposto.

\subsubsection{ANÁLISE DO INDICADOR I4}

Este modelo de indicador visa verificar o cumprimento dos prazos estabelecidos para a área de metrologia na calibração dos instrumentos necessários para o departamento de manufatura e inspeções internas e externas continuarem com suas atividades no prazo estimado.

Revista Ibero-Americana de Estratégia - RIAE, São Paulo, v. 9, n. 3, p. 139-173, set./dez. 2010. 
Aplicação da Metodologia do Balanced Scorecard no Sistema de Avaliação da Qualidade de uma Unidade Estratégica de Negócios

Embora tenha o objetivo de uma verificação pontual de andamento e correção de processos, é necessário para medir a eficiência do departamento na execução de suas atividades, dada a importância dos diferentes instrumentos corretamente aferidos para serem utilizados nos processos seguintes.

Tabela 1 - P2 Indicador de Incidência de Erro.

\begin{tabular}{|l|r|r|r|r|}
\hline \multirow{2}{*}{ Agente Causador } & \multicolumn{5}{|c|}{ Quant. de erros por equipamento } \\
\cline { 2 - 5 } & Equip. 1 & Equip. 2 & Equip. 3 & Equip. 4 \\
\hline Engenharia & 1 & 0 & 0 & 0 \\
\hline Suprimentos & 1 & 0 & 0 & 0 \\
\hline Manufatura & 2 & 0 & 0 & 0 \\
\hline Expedição & 0 & 1 & 0 & 0 \\
\hline Transporte & 0 & 2 & 0 & 0 \\
\hline Montagem no Campo & 0 & 1 & 0 & 0 \\
\hline Nome: Indicador Incidência de Erro \\
$\begin{array}{l}\text { Setor: Qualidade } \\
\text { Perspectiva BSC: Aprendizagem e Crescimento }\end{array}$ \\
\hline
\end{tabular}

Fonte: Elaborado pelos autores.

Considera-se que a tolerância de atrasos para esta medição deve ser nula, a fim de evitar paradas na fábrica e atrasos de projetos que possam resultar em prejuízos financeiros para a organização.

\subsubsection{ANÁLISE DO INDICADOR I5}

Este é um modelo de indicador de desempenho para verificação da eficiência da área do laboratório no cumprimento de suas atividades na execução de ensaios mecânicos destrutivos solicitados pela área de manufatura na qualificação das chapas recebidas e também para analisar o ocorrido quando da detecção de anomalias no processo de montagem dos equipamentos na obra para posterior laudo da engenharia.

Assim como o modelo I4, sua medição é extremamente importante para a garantir que as próximas fases possam ocorrer sem atrasos e tenham a aprovação necessária a fim de evitar prejuízos com a utilização de material indevidos, que não atendam ao especificado.

Revista Ibero-Americana de Estratégia - RIAE, São Paulo, v. 9, n. 3, p. 139-173, set./dez. 2010. 
Sandra Aparecida Nogueira de Oliveira Boffi, Edson Aparecida de Araújo Querido Oliveira, Monica Franchi Carnielo \& Vilma da Silva Santos

\subsubsection{ANÁLISE DO INDICADOR I6}

Este indicador de desempenho tem o mesmo objetivo do Modelo I1, de verificação da eficiência do departamento, porém é destinado à medição da área de Garantia da Qualidade.

Em complemento às observações referentes ao Modelo I1, sugere-se a elaboração de um novo modelo de indicador, mas que ao invés de verificar a eficiência do departamento da Garantia da Qualidade em relação ao seu Budget anual, verifique em termos de cumprimento de prazos e horas orçadas por projeto e por cliente.

Sugere-se criar modelo P3 da mesma forma que o modelo proposto P1, alterando apenas a subárea de Engenharia da Qualidade para Garantia da Qualidade.

\subsubsection{ANÁLISE GERAL DO SISTEMA DE MEDIÇÃO DA QUALIDADE}

Com a análise do sistema de medição da qualidade é possível notar que, todos os seus indicadores estão voltados ao cumprimento ou não das atividades e horas planejadas em seus respectivos prazos.

Da mesma forma, estão direcionados, em sua maioria, para os objetivos somente financeiros e de processos internos, com foco principal em relatar o andamento das atividades e pouca preocupação em serem agentes propulsores de melhorias.

Também se pode observar que a Qualidade utiliza o orçamento como principal ferramenta de controle para garantir seus processos. O Quadro 1 demonstra os modelos atuais utilizados.

\begin{tabular}{|c|l|c|}
\hline ÁREA & \multicolumn{1}{|c|}{ INDICADOR } & PERSPECTIVA \\
\hline Qualidade & I1 - Eficiência da Engenharia da Qualidade & Financeira \\
\hline Qualidade & I1 - Eficiência da Engenharia da Qualidade & Financeira \\
\hline Qualidade & I2 - Eficiência da Inspeção Externa & Financeira \\
\hline Qualidade & I3 - Eficácia da Engenharia da Qualidade & Processos Internos \\
\hline Qualidade & I4 - Eficiência da Metrologia & Processos Internos \\
\hline Qualidade & I5 - Eficiência do Laboratório & Processos Internos \\
\hline Qualidade & I6 - Eficiência da Garantia Qualidade & Financeira \\
\hline
\end{tabular}

Quadro 1 - Classificação dos Indicadores da Qualidade com o BSC Fonte: Elaborado pelos autores.

Revista Ibero-Americana de Estratégia - RIAE, São Paulo, v. 9, n. 3, p. 139-173, set./dez. 2010. 
A síntese dos principais pontos fracos considerados no departamento de Engenharia: foco somente nos resultados financeiros e na verificação dos processos internos, devido a ser área que tem função de aprovar os equipamentos e serviços oferecidos pela empresa. Necessita-se de ferramentas de medição propulsoras de melhorias para todas as áreas da organização, que tenham atuação direta nos projetos.

Embora as metas dispostas nos modelos de indicadores apresentados tenham sido alteradas a fim de salvaguardar as informações oficiais e sigilosas da empresa foco do estudo, que optou por ficar anônima, observou-se que as metas utilizadas pela área da qualidade eram diferentes de zero, mas entende-se que estas deveriam ser zero defeitos a fim de garantir todos os produtos e equipamentos oferecidos pela organização;

Sugestões de melhorias: além dos modelos sugeridos em complemento aos Indicadores I1, I3 e I6, respectivamente, os modelos P1, P2 e P3, sugerem-se a criação de medição para treinamento e motivação da equipe:

- P4 - Indicador de Motivação da Equipe: para facilitar a análise geral da organização quanto à implantação do BSC, sugere-se utilizar em caso aplicável o mesmo modelo de indicador em todos os departamentos. Segue o modelo P4, proposto, apresentado na Figura 8;

- P5 - Indicador de Treinamento da Equipe: no caso da área da qualidade, por se tratar de uma área responsável por aprovar com a utilização de inspeções todos os processos e equipamentos da empresa, considera-se importante à formação de especialistas em equipamentos e processos, com o objetivo de obter uma maior oportunidade de sugestões de melhorias e maior assertividade nas aprovações.

Revista Ibero-Americana de Estratégia - RIAE, São Paulo, v. 9, n. 3, p. 139-173, set./dez. 2010. 
Sandra Aparecida Nogueira de Oliveira Boffi, Edson Aparecida de Araújo Querido Oliveira, Monica Franchi Carnielo \& Vilma da Silva Santos

Figura 8 - P4 Indicador de Motivação da Equipe.

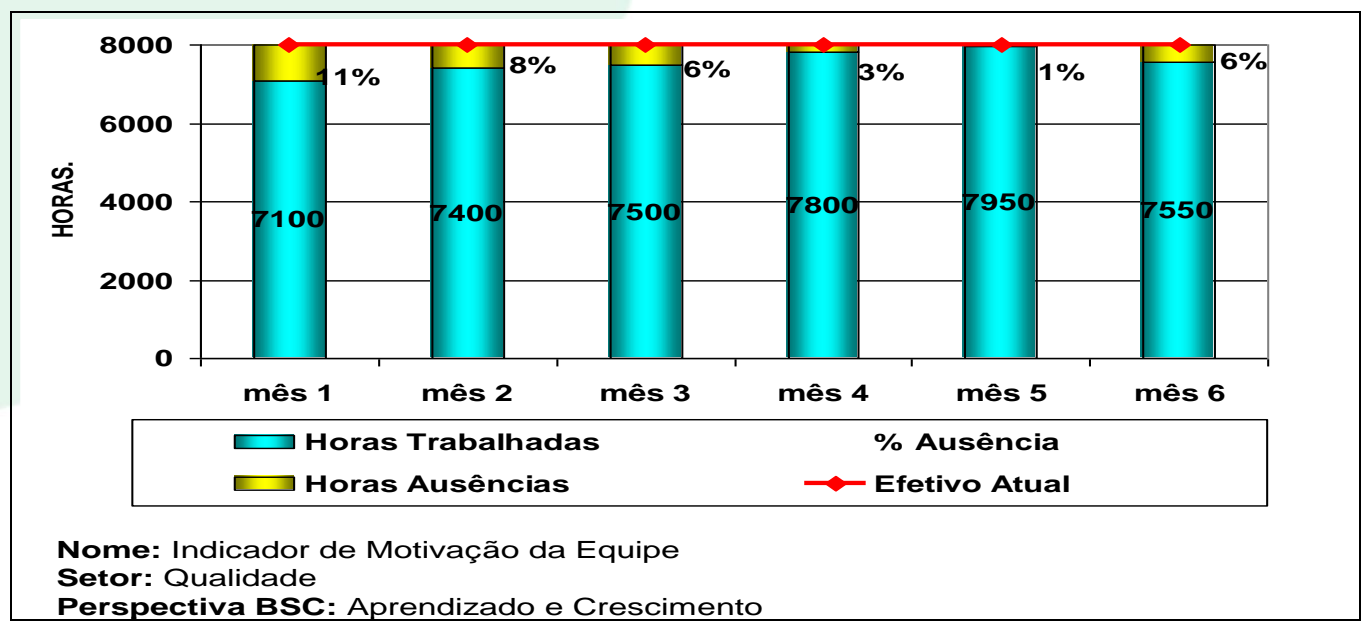

Fonte: Elaborado pelos autores.

Sugere-se definir um indicador que estabeleça diferentes treinamentos para os membros da equipe da qualidade, conforme a necessidade detectada. Pode-se optar por verificar o conhecimento atual da equipe e identificar os processos mais complexos para melhor direcionar os treinamentos. A Tabela 2 tem o objetivo de apresentar essa sugestão.

Em síntese das propostas elaboradas para o departamento, a fim construir um sistema de medição balanceado de acordo com o modelo proposto BSC. Afirma-se que a área de qualidade deve possuir um sistema de medição que incentive melhorias para toda a organização.

Sendo esta área a responsável pela provação de todos os equipamentos e produtos oferecidos pela empresa, sugere-se que este departamento seja o verificador da correta utilização e atualização dos indicadores de desempenho de toda organização no prazo estabelecido e de acordo com métodos escolhidos para sua disseminação e correta compreensão.

Quando da implantação do BSC em nível de Unidade Estratégica de Negócios, sugere-se que esta área atue a fim de acompanhar a evolução desta aplicação, a fim de se especializar e preparar treinamentos quando necessários e oportunos aos processos.

Revista Ibero-Americana de Estratégia - RIAE, São Paulo, v. 9, n. 3, p. 139-173, set./dez. 2010. 
Aplicação da Metodologia do Balanced Scorecard no Sistema de Avaliação da Qualidade de uma Unidade Estratégica de Negócios

Tabela 2 - P5 Indicador de Treinamento da Equipe.

\begin{tabular}{|c|c|c|c|c|}
\hline \multirow{2}{*}{$\begin{array}{c}\text { Tipo de } \\
\text { Equipamento }\end{array}$} & \multicolumn{5}{|c|}{ Estratégia de Treinamento mensal } \\
\cline { 2 - 5 } & $\begin{array}{l}\text { Inspetor } \\
\text { nível 1 }\end{array}$ & $\begin{array}{l}\text { Inspetor } \\
\text { nível 2 }\end{array}$ & $\begin{array}{l}\text { Inspetor } \\
\text { Externo }\end{array}$ & $\begin{array}{c}\text { Técnico em } \\
\text { Manuais }\end{array}$ \\
\hline Equip. 1 & 4 horas & 0 & 0 & 0 \\
\hline Equip. 2 & 2 horas & 3 horas & 0 & 0 \\
\hline Equip. 3 & 0 & 3 horas & 0 & 0 \\
\hline Equip. 4 & 0 & 1 & 10 horas & 0 \\
\hline Equip. 5 & 0 & 2 & 0 & 10 horas \\
\hline Equip. 6 & 0 & 1 & 0 & 15 horas \\
\hline $\begin{array}{l}\text { Nome: Indicador de Treinamento da Equipe } \\
\text { Setor: Qualidade } \\
\text { Perspectiva BSC: Aprendizagem e Crescimento }\end{array}$ \\
\hline
\end{tabular}

Fonte: Elaborado pelos autores.

Porém, analisando somente o sistema de medição desta área, segue o novo quadro de indicadores sugerido para utilização na área da qualidade. Observa-se que este novo quadro procura equilibrar a elaboração de indicadores de desempenho nas perspectivas propostas pelo BSC, aperfeiçoando o quadro mais restrito existente anteriormente a análise.

O novo sistema de medição proposto pode ser observado no Quadro 2.

\begin{tabular}{|l|c|l|}
\hline \multicolumn{1}{|c|}{ INDICADOR } & SUGESTÃo & \multicolumn{1}{|c|}{ PERSPECTIVA BSC } \\
\hline I5 - Eficiência da Engenharia da Qualidade & Manter & Financeira \\
\hline I6 - Eficiência da Inspeção Externa & Manter & Financeira \\
\hline I7 - Eficácia da Engenharia Qualidade & Manter & Processos Internos \\
\hline I8 - Eficiência da Metrologia & Manter & Processos Internos \\
\hline I9 - Eficiência do Laboratório & Manter & Processos Internos \\
\hline I10 - Eficiência da Garantia da Qualidade & Manter & Financeira \\
\hline P6 - Atendimento ao Cliente (Eng.Qualidade) & Modelo proposto & Cliente \\
\hline P7 - Incidência de Erro & Modelo proposto & Aprendizado e Crescimento \\
\hline P8 - Atendimento ao Cliente (Gar. da Qualidade) & Modelo proposto & Cliente \\
\hline P9 - Motivação da Equipe & Modelo proposto & Aprendizado e Crescimento \\
\hline P10 - Treinamento da Equipe & Modelo proposto & Aprendizado e Crescimento \\
\hline
\end{tabular}

Quadro 2 - Proposta de um Novo Quadro de Indicadores para a Qualidade Fonte: Elaborado pelos autores.

Revista Ibero-Americana de Estratégia - RIAE, São Paulo, v. 9, n. 3, p. 139-173, set./dez. 2010. 
Sandra Aparecida Nogueira de Oliveira Boffi, Edson Aparecida de Araújo Querido Oliveira, Monica Franchi Carnielo \& Vilma da Silva Santos

Portanto, como resultado deste trabalho, considera-se que, de acordo com a rapidez em que se propagam as novas tecnologias no ambiente atual é necessário que as organizações consigam definir metodologias para melhor operacionalizar a sua estratégia.

Uma das principais ferramentas a serem empregadas é a utilização de um sistema de medição balanceado, consistente e coerente com os objetivos estabelecidos pela própria organização.

\section{CONCLUSÃO}

As organizações atuais, em virtude das rápidas alterações no contexto mundial necessitam de um sistema de medição de desempenho, capaz de atuar como ferramenta de gestão para o apoio estratégico auxiliando no sistema de decisão, e que atue como agente propulsor para a integração de todas as medidas essenciais, necessárias para a implantação e acompanhamento dos objetivos e metas estabelecidas.

Neste ambiente, o investimento na função administrativa Controle, responsável pelo monitoramento das atividades e suas correções se tornou primordial para condução da empresa na tomada de decisão consistente com os planos e padrões estabelecidos, com o monitoramento da regularidade, ajustes de processos e incentivos da melhoria contínua.

A introdução de novos sistemas de medição que acompanhassem o dinamismo e as situações de incertezas das empresas modernas tornou-se essencial para fornecer subsídios à implantação da estratégia e para a visão ampla do negócio.

Neste contexto, tem-se a evolução do sistema de medição, conseguida com a utilização de modelos mais abrangentes, preocupados com o balanceamento das medidas em outros focos além do financeiro.

Porém, é interessante observar, que embora os modelos de indicadores de desempenho existentes atualmente possuam focos mais amplos e sejam mais completos nas medições de diferentes medidas ainda não se encontram em uma forma acabada, necessitando de investimento durante o seu processo de implantação, acompanhamento e aperfeiçoamento a fim de atender as necessidades e particularidades de cada empresa.

A ferramenta escolhida para avaliação do desempenho que mapeasse a empresa objeto do estudo como um todo foi o Balanced Scorecard (BSC), cujo objetivo é traduzir a missão e a estratégia de uma organização em medidas mensuráveis. Reúne informações para o balanceamento 
do sistema de medição em um conjunto de indicadores dispostos em quatro perspectivas: financeira, dos clientes, dos processos internos e aprendizado e crescimento.

$\mathrm{Na}$ utilização da metodologia foram observadas melhorias assim que os gestores e suas respectivas equipes incorporem os objetivos do BSC e entendam a sua importância para a empresa. Além da construção de indicadores balanceados, a organização deve estar atenta para o desenvolvimento de modelos de indicadores de desempenho com as características ideais, conforme abordado na revisão de literatura.

A aplicação do BSC na Qualidade proporcionou condições para a alta administração da UEN analisar se os objetivos estabelecidos para os departamentos e para a própria unidade estão sendo atingidos. Poderá acompanhar a performance das superintendências em relação à missão da organização e avaliar se está coerente com a visão em longo prazo para o propósito a que a empresa se destina.

Entendendo-se o BSC como ferramenta para gestão da estratégia, sua utilização pode oferecer diversas possibilidades, como medição do andamento dos departamentos, dos projetos, das melhorias, entre outros, tudo alinhado no sentido de cumprir a missão e a visão geral da administração corporativa.

Os departamentos, quando vistos como apenas partes de uma UEN, somente respondem pelo desempenho atingido ao longo do tempo, mas, quando vistos como os responsáveis pelo desempenho da UEN, devem ter foco na realização da estratégia da organização. Assim, será possível alterar o foco atual dos departamentos em atingir somente o orçamento para a visão de responsabilidade nos resultados globais da UEN e da empresa como um todo.

Para o sucesso na implantação do BSC deve-se conscientizar todos os envolvidos. Em outras palavras, o processo de transformar a estratégia em ação pode, então, ser entendido como a colocação dos planos estratégicos em práticas operacionais a serem vivenciadas em todos os níveis da organização, pois a estratégia é elaborada pela alta administração, mas seus resultados são obtidos em nível de UEN e seus departamentos e é no nível operacional que a estratégia é executada e que as perspectivas do BSC se materializam.

Para que a pesquisa fosse viabilizada, o primeiro passo foi definir uma proposta de análise dos dados coletados apoiada no BSC, já que o mesmo prevê uma sistemática de implantação (topdown) da alta administração para os níveis mais baixos, mas, no entanto é versátil na adaptação às diversas necessidades e realidade de cada empresa.

Revista Ibero-Americana de Estratégia - RIAE, São Paulo, v. 9, n. 3, p. 139-173, set./dez. 2010. 
Sandra Aparecida Nogueira de Oliveira Boffi, Edson Aparecida de Araújo Querido Oliveira, Monica Franchi Carnielo \& Vilma da Silva Santos

Como resultado da pesquisa, observa-se que os indicadores de desempenho escolhidos não são imutáveis, mas sua principal finalidade é cascatear os objetivos da organização e representar um conjunto de medição adaptável as possíveis mudanças advindas da evolução e aperfeiçoamento dos processos.

No geral, pode-se concluir por meio das respostas obtidas na pesquisa que as ferramentas que melhor representam os dados de cada unidade estratégica de negócios para a administração corporativa, são os indicadores de desempenho quando elaborados a partir da missão e da estratégia da organização e têm como objetivo agregar as informações de todas as UENs, disseminar as políticas a serem seguidas e auxiliar na definição das estratégias.

Conclui-se também que a maneira correta para a estruturação, subdivisão e implementação de um sistema de medição que garanta a visão correta para a organização de sua posição, assim como a focalização de onde devem ser disponibilizados os esforços no que é considerado crítico para que sejam atingidos as metas e resultados futuros esperados é a utilização d uma metodologia de implementação deste sistema, no caso deste trabalho, foi à utilização do BSC.

No caso especifico da empresa pesquisa, os indicadores não estavam de acordo com os objetivos estratégicos da organização, tal afirmação pode ser confirmada verificando-se que os departamentos possuíam uma tendência em apenas acompanhar o andamento das atividades em relação ao orçado.

O sistema de medição deve ser criado com foco no atendimento da estratégia estabelecida, para isso os alguns dos critérios a serem utilizados são: entendimento da política, engajamento de todos os membros da equipe, definição de uma metodologia a ser seguida e pontualidade na atualização deste sistema.

Conclui-se, portanto, que a utilização de um sistema de medição somente será eficiente, caso desenvolvido de forma estruturada e integrada com os objetivos gerais da organização.

\section{REFERÊNCIAS}

Boffi, S. A. N. O. (2007). Análise dos indicadores de desempenho das metas da administração corporativa: um estudo de caso. Dissertação de Mestrado, Universidade de Taubaté, Taubaté.

Campos, A. J. (1998). Cenário balanceado: painel de indicadores para a gestão estratégica dos negócios. São Paulo: Aquariana.

Revista Ibero-Americana de Estratégia - RIAE, São Paulo, v. 9, n. 3, p. 139-173, set./dez. 2010. 
Aplicação da Metodologia do Balanced Scorecard no Sistema de Avaliação da Qualidade de uma Unidade Estratégica de Negócios

Campos, V. F. (1999). TQC controle da qualidade total (no estilo japonês) (8a ed.). Belo Horizonte: Editora de Desenvolvimento Gerencial.

Cervo, A. L., \& Bervian, P. A. (1996). Metodologia científica (4a ed.). São Paulo: Makron Books.

Costa, A. P. P. (2001). Contabilidade gerencial: um estudo sobre a contribuição do Balanced Scorecard. Dissertação de Mestrado, Faculdade de Economia, Administração e Contabilidade, Universidade de São Paulo, São Paulo.

Daft, R. L. (2005). Administração (6a ed.). São Paulo: Thomson.

Farmer, S. A. (2004). A performance measurement framework for internal audit. Thesis Master of Science, University of Central England Business School, Birmingham.

Figueiredo, M. A. D. (2003). Sistemas de medição de desempenho organizacional: um modelo para auxiliar sua auto-avaliação. Tese de Doutorado, Universidade Federal do Rio de Janeiro, Rio de Janeiro.

Gomes, J. S., \& Salas, J. M. A. (2001). Controle de gestão: uma abordagem contextual e organizacional (3a ed.). São Paulo: Atlas.

Hitt, M. A., Ireland, R. D., \& Hoskisson, R. E. (2002). Administração estratégica. São Paulo: Pioneira Thomson Learning.

Kallás, D. (2003). Balanced scorecard: aplicação e impactos: um estudo com jogos de empresas. Dissertação de Mestrado, Faculdade de Economia, Administração e Contabilidade, Universidade de São Paulo, São Paulo.

Kaplan, R. S., \& Norton, D. P. (2004). Mapas estratégicos: convertendo ativos intangíveis em resultados tangíveis (A. C. C. Serra, Trad.) (9a ed.). Rio de Janeiro: Campus.

Kaplan, R. S., \& Norton, D. P. (1997). A estratégia em ação: balanced scorecard (8a ed.). Rio de Janeiro: Campus.

Lawton, R. (2002). Balance your balanced scorecard: categories of measures should reflect key values of both organization and customers. Quality Progress, 35(3), 66-71.

Martins, R. A., \& Costa Neto, P. L. O. (1998). Indicadores de desempenho para a gestão pela qualidade total: uma proposta de sistematização. Gestão \& Produção, 5(3), 298-311.

Meadows, D. (1998). Indicators and information systems for sustainable development: a report to the Balaton Group. Hartland: The Sustainability Institute.

Revista Ibero-Americana de Estratégia - RIAE, São Paulo, v. 9, n. 3, p. 139-173, set./dez. 2010. 
Sandra Aparecida Nogueira de Oliveira Boffi, Edson Aparecida de Araújo Querido Oliveira, Monica Franchi Carnielo \& Vilma da Silva Santos

Montgomery, C. A., \& Porter, M. E. (Org.) (1998). Estratégia: a busca da vantagem competitiva (3a ed.). Rio de Janeiro: Campus, 501 p.

Moreira, D. A. (1996). Dimensões do desempenho em manufaturas e serviços. São Paulo: Pioneira.

Pandolfi, M. (2005). Sistemas de medição e avaliação de desempenho organizacional: contribuição para a gestão das metas globais a partir de performances individuais. Tese de Doutorado, Escola Politécnica, Universidade de São Paulo, São Paulo.

Rebouças, D. P. R. O. (2003). Holding, administração corporativa e unidade estratégica de negócio (3a ed.). São Paulo: Atlas.

Slack, N., Chambers, S., \& Harland, C. (1997). Administração da produção (A. B. Brandão, Trad.). São Paulo: Atlas.

Telles, R. (2003). Marketing empresarial. São Paulo: Saraiva.

Recebido: 01/08/2010

Aprovado: 15/11/2010

Revista Ibero-Americana de Estratégia - RIAE, São Paulo, v. 9, n. 3, p. 139-173, set./dez. 2010. 